\title{
Effects of Education Level of Father and Mother on Perceptions of Breastfeeding
}

\author{
Bilkis Banu $^{1}$, Khurshida Khanom ${ }^{2}$
}

\begin{abstract}
Background: It is well known that education level of father and mother is an important factor to achieve breastfeeding. But, according to some literature, there is still controversy that education of parents is really a major factor for perceptions of breastfeeding. Objective: To determine the effects of education level of father and mother on perception or knowledge of breastfeeding. Materials and Methods: This descriptive cross sectional study was conducted in the selected areas of Dhaka city amongst all (202) mothers and fathers of the children of 2 years or more than 2 years of age. Data were collected through pretested questionnaire by face to face interview. Data were analyzed by appropriate univariate analysis. Results: Among the study subjects majority of mothers (49.5\%) were of secondary and higher secondary levels and fathers (35.6\%) were of graduate and above level of education. Educated mothers (secondary $72 \%$ and graduate 90.9\%) were more likely to give colostrums to their babies than illiterate mothers (38.9\%). Although duration of exclusive breastfeeding and breastfeeding were not associated with maternal education, but knowledge on breastfeeding was highly significant (good knowledge) for higher educated parents (mothers $63.6 \%$ and fathers $52.8 \%)$ as compared to illiterate or low educated parents $(P<0.001)$. Majority of parents got information from doctors/health workers rather than book or other sources regarding usefulness of breast milk. Conclusion: The study reveals that perceptions of breastfeeding are higher in educated parents than illiterate parents. To reach at an ever satisfactory level of breastfeeding practice, more attention and education need to be given amongst the general people.
\end{abstract}

Key words: Education Level, Perceptions, Breastfeeding

J Enam Med Col 2012; 2(2): 67-73

\section{Introduction}

The word nutrition is originated from the word 'nutricus' meaning to suckle at the breast. The three determinants of good nutrition - food security, disease control and caring are contained in the single activity of breastfeeding. ${ }^{1}$ Breast milk is a perfect nutrient and breastfeeding is the gold standard of infant feeding. ${ }^{2}$

World leaders in the United Nations Millennium Summit in 2000 agreed on eight goals for human development of which two critical goals for the year 2015 are to reduce the maternal mortality ratio by three-fourths and to reduce deaths of children under 5 by two-thirds. Perhaps no single public health intervention will be saving more lives and promote health of women and children as does breastfeeding. The mother and the child as a dyad i.e. one inseparable unit is best exemplified by the act of breastfeeding. ${ }^{3}$ Breastfeeding plays an important and influential role in child survival and offers immunological protection to an infant against early morbidity and mortality. In developing countries, breastfed infants experience substantially lower

1. Lecturer, Department of Health Education and Health Promotion, Bangladesh Institute of Health Sciences (BIHS), Dhaka

2. Professor, Department of Health Education and Health Promotion, Bangladesh Institute of Health Sciences (BIHS), Dhaka

Correspondence Bilkis Banu,Email: bil_kis80@yahoo.com,hsa@hcdp-bd.org,Phone:008801716245245 
morbidity and mortality risks than infants who are not breastfed, particularly in the first year of life. ${ }^{4-9}$

Breast milk is well known to have positive impact on child health. Research in public health has found that essential antibodies are present in the first breast milk (colostrum) and these antibodies provide the newborn with the needed protection against some infectious diseases and thus enhance the resistance to infectious disease attack. ${ }^{10}$ For mothers, early suckling stimulates the release of a hormone that helps the uterus to involute to its normal size after delivery. ${ }^{11}$

The advantages of breastfeeding are widely documented $^{12}$ and in general undisputed. In the developing world, breastfeeding is strongly correlated to a reduction in infant mortality and morbidity and in the developed world there is overwhelming evidence to suggest that breastfeeding offers babies some protection from sudden infant death syndrome.

Some research findings not only outline the advantages of breastfeeding, but also highlight the disadvantages of formula feeding, even in developed countries. Contrary to research findings that colostrum is essential for the health of the baby, there is the belief in some traditional societies that colostrum is harmful for the baby. Results from a study on rural mothers in Egypt show that some mothers believe that the 'real' milk doesn't appear for several days after birth and colostrum has no nutritive role or is even harmful for the babies. ${ }^{13}$ Therefore many mothers do not breastfeed their babies during the first few hours after birth. It can be seen from the study result that lack of education is one of the most important factor that interact the implementation of breastfeeding practice at a satisfactory level. ${ }^{14}$

Due to the benefits of the first colostrum, much research has been done on the determinants of breastfeeding initiation to examine factors affecting the decision of mother to initiate early breastfeeding. Previous studies have found that many socioeconomic and cultural factors are important determinants of breastfeeding. ${ }^{15}$ Education of parents is considered as the most important factor in determining the initiation, practice and knowledge of breastfeeding.
Education is the single most important indicator of the socioeconomic status of an individual which affects almost all aspects of human life, including demographic and health behaviors. ${ }^{16}$ An illiterate parent cannot realize the danger of substitute tin milk and benefits of breast milk. For an example in urban slums of Dhaka city in Bangladesh exclusive breastfeeding is 54\%. ${ }^{17}$ Among many important factors, an important issue is the lack of education. Most of our parents, who are illiterate, cannot choose the appropriate food for their children. On the other hand, some educated parents also cannot realize the benefits of breastfeeding because of their little knowledge about breast milk.

Bangladesh is a regional leader in breastfeeding. According to the national level data, the prevalence of colostrum feeding has increased over the years, from $87 \%$ to $92 \% .^{18,19}$ In spite of this success, exclusive breastfeeding level could not reach at a satisfactory level.

Mothers' education appears to be an important factor for children's nutrition status. Association between increased maternal education and child survival and development are consistent and strong. More educated mothers make better use of health service and provide better child care including breastfeeding. Educated mothers can easily realize the advantages of breast milk and disadvantages of breast milk substitute better than an illiterate mother. An educated mother surely brings up her child in a better way than an uneducated one.

Father's education is necessary for sound child nutrition status. Essential care for the children also depends on father's education level because the main household income earners in Bangladesh are predominantly male. Although many of us tend to think of the breastfeeding relationship as purely a mother and child concern, but fathers are also essential to a successful breastfeeding experience.

A few examples were acclaimed by some of researchers where several advantages were described when both parents are active and engaged in taking care of children, compared to only one active parentfathers develop their empathic ability, considering that women are more trained at this; a more equal division of responsibilities increases the possibilities for both parents to fill many roles within the family complex, which tend to make them more satisfied 
with their lives; cultures where fathers are more committed to childcare seem to produce less hostility and violence between men and women, compared to other cultures. ${ }^{20}$

Several researches have been done to find out the association between parents' education and breastfeeding practice. Some results show positive correlation (initiation of breastfeeding ${ }^{21}$, benefits of breastfeeding etc), some results show negative association (duration of breastfeeding, colostrum feeding 22,23 etc). So, still there is controversy that education of parents is really a major factor for knowledge and practice of breastfeeding. Under these circumstances, the study was undertaken to determine the effects of education level of father and mother on perception or knowledge of breastfeeding.

\section{Materials and Methods}

This descriptive cross sectional study was conducted at two villages (Rasulbag and Chadbag) of Ashkona area under Dakshinkhan Thana of Dhaka city in Bangladesh over a period of 6 months in 2009. Mothers and fathers of the children of 2 years or above 2 years were the study population. Purposive sampling technique was applied to select 202 subjects. Prior to data collection semi-structured questionnaire was prepared and pretested. Data were collected by face to face interview and the observation procedure was also used to find the breastfeeding knowledge, practice and belief on perceptions of breastfeeding of the parents. Collected data were rechecked and verified on regular basis for accuracy, consistency and completeness. After the interview, those who answered all the questions correct, were designated as having good knowledge (score 7), who gave average correct answers were considered as having average knowledge (score 4-6), and who gave partial correct answers or incorrect answers were designated as having poor knowledge (score 0-3). Data were coded and analysis was done by computer aided statistical software SPSS, version 11.5. Chi-square tests were done. The descriptive statistics, which included the frequencies, percentage, important tables, cross-tables and charts were then prepared on the basis of the findings relevant to the study.

\section{Results}

Overall distribution of education level among the respondents is described in Table I where maximum number $(50,49.5 \%)$ of mothers were from Secondary and Higher Secondary (SSC \& HSC) level of education and $36(35.6 \%)$ fathers were of graduate and above level of education.

Table I: Distribution of parents by their education level $(n=202)$

\begin{tabular}{lcc} 
Level of education & $\begin{array}{c}\text { Mothers } \\
\text { No (\%) }\end{array}$ & $\begin{array}{c}\text { Fathers } \\
\text { No (\%) }\end{array}$ \\
No education & $17(17.8 \%)$ & $13(12.9 \%)$ \\
Up to Primary (I-V) & $22(21.8 \%)$ & $18(17.9 \%)$ \\
Secondary \& Higher & $50(49.5 \%)$ & $29(28.7 \%)$ \\
Secondary (VI-XII) & & \\
Graduate or above & $11(10.9 \%)$ & $36(35.6 \%)$ \\
Missing & - & $5(4.9 \%)$ \\
Total & $101(100.0 \%)$ & $101(100.0 \%)$ \\
\hline
\end{tabular}

The study shows that $61.1 \%$ illiterate respondents gave their children sugar water, honey etc. as initial food. On the other hand, $90.9 \%$ graduate or above degree holder mothers gave their children colostrum as initial food just after birth which is highly significant (Fig 1).

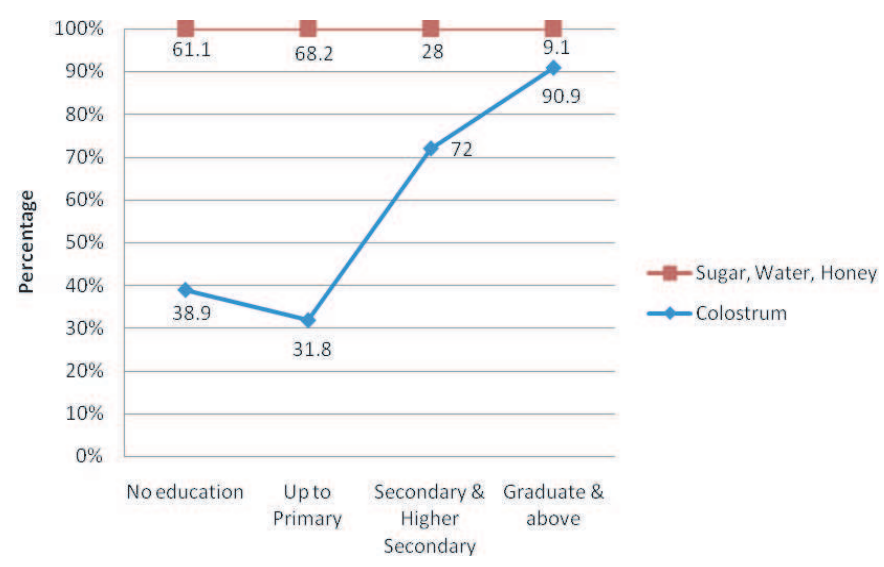

Level of Education

Fig 1. Effects of mothers' education on the types of initial food given to the newborn child $\left(\chi^{2}=\right.$ 17.90; df $=3 ; \mathrm{P}<0.05 ; \mathrm{n}=101$ )

Surprisingly, mothers' education has been found to have no significant effect on the duration of exclusive breastfeeding and breastfeeding practice. Mothers are practicing breastfeeding even though they are not educated (Tables II \& III). 
Education of mother is found significantly associated with total knowledge score on various components of breastfeeding which includes initial feeding, exclusive breastfeeding, nutritive value of breast milk, importance of breastfeeding, disadvantages of breast milk substitute, colostrum rejection, and mother's health. Knowledge score is high (good knowledge) in mostly higher educated mothers $(63.6 \%)$ as compared to illiterate or low educated mother $(\mathrm{P}<0.05)$ (Table IV). Similarly, fathers' education and total knowledge score on various components of breastfeeding such as initial feeding, exclusive breastfeeding, nutritive value of breast milk, importance of breastfeeding, rejection of breast milk, mother's health are also significantly associated. Knowledge score is high (good knowledge) in mostly higher educated fathers $(52.8 \%)$ as compared to illiterate or low educated fathers $(\mathrm{P}<0.05)$ (Table $\mathrm{V})$.

Majority (37\%) of mothers were informed regarding usefulness of breast milk from both doctor/health workers and mass media like radio/TV. On the other hand, majority (44\%) of fathers got information from only doctor/health workers (Table VI).

Table II: Effects of mothers' education level on duration of breastfeeding practice

\begin{tabular}{|c|c|c|c|c|}
\hline \multirow[t]{2}{*}{ Level of education } & \multicolumn{2}{|c|}{ Duration of breastfeeding } & \multirow{2}{*}{ Total } & \multirow{2}{*}{ Level of significance } \\
\hline & 2 years & $<2$ yrs or $>2$ yrs & & \\
\hline \multirow{2}{*}{ No education } & 10 & 8 & 18 & \\
\hline & $55.60 \%$ & $44.40 \%$ & $100.00 \%$ & \\
\hline \multirow[t]{2}{*}{ Up to Primary } & 8 & 14 & 22 & \\
\hline & $36.40 \%$ & $63.60 \%$ & $100 \%$ & NS \\
\hline \multirow{2}{*}{$\begin{array}{l}\text { Secondary \& Higher } \\
\text { Secondary }\end{array}$} & 34 & 16 & 50 & $\mathrm{P}>0.05(0.09)$ \\
\hline & $68.00 \%$ & $32.00 \%$ & $100.00 \%$ & \\
\hline \multirow[t]{2}{*}{ Graduate or above } & 7 & 4 & 11 & \\
\hline & $63.60 \%$ & $36.40 \%$ & $100.00 \%$ & \\
\hline \multirow[t]{2}{*}{ Total } & 59 & 42 & 101 & \\
\hline & $58.40 \%$ & $41.60 \%$ & $100.00 \%$ & \\
\hline
\end{tabular}

Table III: Effects of mothers' education level on exclusive breastfeeding (EBF)

\begin{tabular}{|c|c|c|c|c|c|}
\hline \multirow[t]{2}{*}{ Level of education } & \multicolumn{3}{|c|}{ Duration of EBF (months) } & \multirow[t]{2}{*}{ Total } & \multirow[t]{2}{*}{ Level of significance } \\
\hline & $0-1$ & $>1$ to $<6$ & $6+$ & & \\
\hline \multirow[t]{2}{*}{ No education } & 6 & 7 & 5 & 18 & \multirow{10}{*}{$\begin{array}{c}\mathrm{NS} \\
\mathrm{P}>0.05(0.80)\end{array}$} \\
\hline & $33.30 \%$ & $38.90 \%$ & $27.80 \%$ & $100.00 \%$ & \\
\hline \multirow[t]{3}{*}{ Up to Primary } & 5 & 7 & 10 & 22 & \\
\hline & $22.70 \%$ & $31.80 \%$ & $45.50 \%$ & $100.00 \%$ & \\
\hline & 10 & 18 & 22 & 50 & \\
\hline $\begin{array}{l}\text { Secondary \& Higher } \\
\text { Secondary }\end{array}$ & $20.00 \%$ & $36.00 \%$ & $44.00 \%$ & $100.00 \%$ & \\
\hline \multirow[t]{2}{*}{ Graduate or above } & 4 & 3 & 4 & 11 & \\
\hline & $36.40 \%$ & $27.30 \%$ & $36.30 \%$ & $100.00 \%$ & \\
\hline \multirow[t]{2}{*}{ Total } & 25 & 35 & 41 & 101 & \\
\hline & $24.80 \%$ & $34.70 \%$ & $40.60 \%$ & $100.00 \%$ & \\
\hline
\end{tabular}


Table IV: Effects of education level of mother on total breastfeeding knowledge score

\begin{tabular}{lccccc} 
Level of education & \multicolumn{3}{c}{ Category of knowledge } & Total & Level of significance \\
& Poor & Average & Good & \\
No education & 4 & 12 & 2 & 18 \\
\cline { 2 - 5 } & $22.20 \%$ & $66.70 \%$ & $11.10 \%$ & $100.00 \%$ \\
\hline Up to Primary & 3 & 14 & 5 & 22 \\
\cline { 2 - 5 } & $13.64 \%$ & $63.64 \%$ & $22.72 \%$ & $100 \%$ \\
\hline Secondary \& Higher Secondary & 3 & 30 & 17 & 50 \\
\cline { 2 - 5 } & $6.00 \%$ & $60.00 \%$ & $34.00 \%$ & $100.00 \%$ \\
\hline Graduate or above & 0 & 4 & 7 & 11 \\
\hline Total & $0.00 \%$ & $36.40 \%$ & $63.60 \%$ & $100.00 \%$ \\
& 10 & 60 & 31 & 101 \\
\cline { 2 - 6 } & $9.90 \%$ & $59.40 \%$ & $30.70 \%$ & $100.00 \%$ \\
\hline
\end{tabular}

$\chi^{2}$ value $=12.911 ; \mathrm{df}=6$

Table V: Effect of fathers' education level on total breastfeeding knowledge score

\begin{tabular}{|c|c|c|c|c|c|}
\hline \multirow[t]{2}{*}{ Level of education } & \multicolumn{3}{|c|}{ Category of knowledge } & \multirow[t]{2}{*}{ Total } & \multirow[t]{2}{*}{ Level of significance } \\
\hline & Poor & Average & Good & & \\
\hline \multirow[t]{2}{*}{ No education } & 10 & 3 & 0 & 13 & \multirow{10}{*}{$\mathrm{P}<0.05(0.000)$} \\
\hline & $76.90 \%$ & $23.10 \%$ & $0.00 \%$ & $100 \%$ & \\
\hline \multirow[t]{2}{*}{ Up to Primary } & 11 & 5 & 2 & 18 & \\
\hline & $61.10 \%$ & $27.80 \%$ & $11.10 \%$ & $100 \%$ & \\
\hline \multirow[t]{2}{*}{ Secondary \& Higher Secondary } & 7 & 13 & 9 & 29 & \\
\hline & $24.20 \%$ & $44.80 \%$ & $31.00 \%$ & $100 \%$ & \\
\hline \multirow[t]{2}{*}{ Graduate or above } & 6 & 11 & 19 & 36 & \\
\hline & $16.70 \%$ & $30.50 \%$ & $52.80 \%$ & $100 \%$ & \\
\hline \multirow[t]{2}{*}{ Total } & 34 & 32 & 30 & 96 & \\
\hline & $35.40 \%$ & $33.30 \%$ & $31.30 \%$ & $100 \%$ & \\
\hline
\end{tabular}

$\chi^{2}$ value $=27.842 ; \mathrm{df}=6$

Table VI: Parents' sources of information regarding usefulness of breast milk

\section{Discussion}

The result from this study indicates that the effect of maternal education level on the practice of initial

\begin{tabular}{lcc} 
Sources of information & $\begin{array}{c}\text { Mothers } \\
\text { No (\%) }\end{array}$ & $\begin{array}{c}\text { Fathers } \\
\text { No (\%) }\end{array}$ \\
\hline Family members & $16(15.8 \%)$ & $11(11.5 \%)$ \\
Doctor/Health worker & $37(36.6 \%)$ & $42(43.8 \%)$ \\
Radio, TV & $38(37.6 \%)$ & $33(34.4 \%)$ \\
Book & $8(7.9 \%)$ & $10(10.3 \%)$ \\
Others & $2(2.0 \%)$ & $0(0.0 \%)$ \\
Total & $101(100.0 \%)$ & $96(100.0 \%)$ \\
\hline
\end{tabular}
feeding is highly significant. Mothers with either secondary school education $(72 \%)$ or graduate degree $(90.9 \%)$ are more likely to give colostrums to their babies just after birth than illiterate mothers (38.9\%). Controversial findings have been shown in another study that all illiterate mothers (100\%) practiced colostrum feeding and $94.12 \%$ of literate mothers did it. ${ }^{24}$

The association between breastfeeding and education has been noted previously in many researches. ${ }^{14,25}$ Similar findings have been found in 
this study that education of parents significantly associated with knowledge score. Knowledge score is high (good knowledge) for higher educated parents (graduate mother 63.6\%; father 52.8\%). Average educated (SSC or HSC) parents (mother $60 \%$; father $44.8 \%$ ) have got average knowledge score. On the other hand, illiterate parents found to have poor knowledge.

In this study, duration of exclusive breastfeeding and breastfeeding are not associated with maternal education. Almost similar findings were shown in other studies. ${ }^{26-29}$ This finding indicates that mothers may breastfeed their children by following traditional practices, even they are less educated or less knowledgeable on breastfeeding.

The study reflects that majority of parents got information regarding usefulness of breast milk from doctors/health workers rather than book or other sources. This result also indicates that less educated parents are usually less book oriented and they will get information on breastfeeding only when they will be familiar with breastfeeding practice. This statement is similar with the study that only $16 \%$ of non-breastfeeding mothers had received information from midwifery staff compared to $36 \%$ of those who had breastfed. ${ }^{30}$

The study indicates that education of fathers and mothers have a very strong impact on perception of breastfeeding. Children who are born to parents with higher education are more likely to be breastfed than the children of less educated mothers. For a higher educated mother (with at least primary school), no matter where she lives, she can have an access to information about colostrum and understand its benefit for her baby, she is also less likely to be influenced by the traditional beliefs and the life-style of the area where she lives. Father's education should be recommended as a major step for successful breastfeeding. So, it is suggested that to maximize the breastfeeding practice, government should continue to improve the level of schooling for women. The breastfeeding promotion program should be expanded more widely in whole country to let all mothers and fathers have the same chance to access to the new information and benefits from the program.

\section{Acknowledgement}

We are indebted to the parents who volunteered in this study. We greatly acknowledge the active involvement of Shaharia Sultana Hasnin throughout the study and her sincere support to publish this paper.

\section{References}

1. Latham MC. Human nutrition in the developing world: Food and Agriculture Organization of the United Nations, Rome; 1997.

2. Austin RC. Breastfeeding is the gold standard! Women's interests. Available at: http://ezinearticles.com/?BreastFeeding-Is-the-Gold-Standard!\&id=6935058.

3. Talukder MQK. Saving lives of women and children through breastfeeding. Bangladesh Breastfeeding Foundation, June 2005.

4. Retherford, Robert D, Choe MK, Thapa S, Bhakta B. Gubhaju. To what extent does breastfeeding explain birth-interval effects on early childhood mortality? Demography 1989; 26: 439.

5. Pebley AR, Stupp PW. Reproductive patterns and child mortality in Guatemala. Demography 1986; 24: 43.

6. Palloni A, Millman S. Effects of inter-birth intervals and breastfeeding on infant and childhood mortality. Population Studies 1986; 40: 215.

7. Millman S. Breastfeeding in Taiwan: trend and differentials 1966-1980. Paper presented at: The $50^{\text {th }}$ annual meeting of the Population Association of America; 1981 March 26-28; Washington, D.C.

8. Grant, James P. The state of The World's Children 1948. UNICEF, (United Kingdom, Oxford University Press); 1984.

9. Knodel J, Kintner H. The impact of breastfeeding patterns on the biometric analysis of infant morality. Demography 1977; 14(4): 391-409.

10. Wray JD. Maternal nutrition, breastfeeding and infant survival. Paper presented at: The Conference on Nutrition and Reproduction; 1977 February; Bethesda, Maryland.

11. Parissi CA, Parissi JMC, Giron JA. Recognition of enteropathogenic Escherichia coli virulence determinants by human colostrum and serum antibodies. Journal of Clinical Microbiology 2000; 38(7): 2696-2700.

12. Mannan HR, Islam MN. Breastfeeding in Bangladesh: patterns and impact on fertility. Asia-Pacific Population Journal 1995; 10(4): 130-148.

13. Hakim IA, Asmawy AEI. Breastfeeding patterns in a rural village in Giza, Egypt. American Journal of Public Health 1992; 82(5): 731-732. 
14. Souza SNDH, Migoto MT, Rossetto EG, Mello DF. Prevalence of breastfeeding and associated factors in the municipality of Londrina (PR, Brazil). Acta Paul Enferm 2012; 25(1): 29-35.

15. Jelliffe DB, Jelliffe EF. World-wide breastfeeding programme - consideration of key components. Journal of Tropical Pediatrics 1989; 35(4): 144-146.

16. Islam MS, Becker S. Interrelationship among certain socioeconomic variables in a rural population of Bangladesh. Rural Demography 1989; 6: 51-65.

17. Khondoker SI, Roy SK, Aliz S. Exclusive breastfeeding rate and related factors in urban slums of Dhaka. Paper presented at: $13^{\text {th }}$ annual scientific conference; 2011 March 14-17; Dhaka, Bangladesh.

18. National institute of population and training: Bangladesh demographic and health survey 2004. Dhaka. 2005.

19. National institute of population and training: Bangladesh demographic and health survey 2007. Dhaka. 2009.

20. Fontem JA. Not for fathers only: men's support for breastfeeding. Available at: http://cameroonlink. blogspot.com/2011_11_01_archive.html.

21. Susin LR, Giugliani ER, Kummer SC, Maciel M, Simon C, Da Silveira LC. Does parental breastfeeding knowledge increase breastfeeding rates? Birth Issues in Perinatal Care 1999; 26(3): 149-156.

22. Giashuddin MS, Kabir M. Breastfeeding duration in Bangladesh and factors associated with it. Indian $\mathrm{J}$ Common Med 2003; 28: 34-38.
23. Giashuddin MS, Kabir M, Duration of breastfeeding in Bangladesh. Indian J Med Res 2004; 119: 267-272.

24. Chatterjee S, Saha S. A study on knowledge and practice of mothers regarding infant feeding and nutritional status of under-five children attending immunization clinic of a medical college. The Internet Journal of Nutrition and wellness 2008; 5(1).

25. Mahoney MC, James DM. Predictors of anticipated breastfeeding in an urban, low-income setting. The Journal of Family Practice 2000; 49(6): 529-533.

26. Popkin BM. Economic determinants of breastfeeding behavior: the case of rural households in Laguna, Philippines. In: Mosley WH (ed). Nutrition and Human Reproduction. New York: Plenum Press, 1978.

27. Mohiuddin, Ahamed M. Breastfeeding in Bangladesh. Journal of Biosocial Science 1986; 18(4): 425-434.

28. Mott, Susan H. A note on the determinants of breastfeeding durations in an African country. Social Biology 1984; 31(3-4): 279-289.

29. Aziz O. The contraceptive role of breastfeeding by educational attainment: an assessment based on Malaysian fertility and family survey. Malaysian Journal of Reproductive Health 1984; 3(1): 77-83.

30. Health promotion agency for Northern Ireland. A summary report on examining changes in knowledge and attitudes towards breastfeeding in Northern Ireland 1999-2004. Belfast: 2011 